\title{
Ankyloglossia: Still a Matter of Controversy
}

\author{
Matin Torabinia ${ }^{1,2}$, Sun-Joo Jang ${ }^{1,2}$, Simon Dunham ${ }^{1,2}$, Steven Rosenblatt ${ }^{3}$ and Bobak Mosadegh ${ }^{1,2 *}$ \\ ${ }^{1}$ Dalio Institute of Cardiovascular Imaging, New York-Presbyterian Hospital and Weill Cornell Medicine, USA \\ ${ }^{2}$ Department of Radiology, Weill Cornell Medicine, USA
}

${ }^{3}$ Department of Otolaryngology-Head and Neck Surgery, Weill Cornell Medicine, USA

*Corresponding author: Bobak Mosadegh, Dalio Institute of Cardiovascular Imaging, New York-Presbyterian Hospital and Weill Cornell Medicine, New York, NY, 10021, USA.

To Cite This Article: Matin T, Sun-Joo J, Simon D, Steven R, Bobak M. Ankyloglossia: Still a Matter of Controversy. 2020 - 8(5). AJBSR. MS.ID.001303. DOI: 10.34297/AJBSR.2020.08.001303.

Received: 阱 April 16, 2020; Published: 眥 April 23, 2020

\begin{abstract}
Symptomatic Ankyloglossia (a.k.a. tongue-tie) is defined as a short or anterior lingual frenulum that interferes with normal tongue mobility. Recently, therehas been a renewed interestamongst healthcare providers regarding the importance of ankyloglossia in clinical practice and its role in breastfeeding difficulties. Despite the attempts of prior studies, there is no consensus on the optimal way to diagnose and manage ankyloglossia. Several classification systems have been published, but none are consistently used and many are difficult for routine clinical applications. Moreover, there is a lack of objective data defining the impairment caused by ankyloglossia or demonstrating efficacy of interventions aimed to treat ankyloglossia. With the ongoing promotion of breast feeding by the US Surgeon General and the American Association of Pediatrics as the primary feeding modality for infants, studying the mechanics, classifications, and outcomes of interventions related to ankyloglossia is an ongoing priority among pediatric healthcare providers.
\end{abstract}

Ankyloglossia is one of the most common anatomic conditions that can contribute to difficulty in breastfeeding. Symptomatic ankyloglossia is defined by tethering of the tongue by an abnormal lingual frenulum that prevents normal tongue mobility, thus interfering with the infant's ability to apply the necessary biomechanical forces to efficiently breastfeed. The incidence of ankyloglossia is reported to be $4-16 \%$ of neonates with a 3:1 male predominance [1-4]. However, there is a wide variability in the reported incidence due to the absence of standardized diagnostic criteria [5].

Breastfeeding has significant health benefits, and is internationally recognized as the most effective preventive health intervention with the potential to prevent $13 \%$ of deaths among children younger than 5 years of age worldwide [6]. Furthermore, breastfeeding is recommended by the American Association of Paediatrics as the primary feeding modality for infants. By choosing to breastfeed instead of using formula, the average family saves approximately $\$ 1,200$ to $\$ 1,500$ in the first year alone; these savings result from reduced healthcare expenditures (i.e. healthier children) and avoiding the costs of formula [7]. In this regard, there have been ongoing clinical and industrial investigations addressing different aspects of breastfeeding, which include, but are not limited to, nutrition quality, breastfeeding duration, positioning, sucking and swallowing frequency, and latching effectiveness $[8,9]$.

Unfortunately, many mothers report difficulty with breastfeeding, specifically, difficulty or pain with the infant latching to the mother's breast. Studies have shown that these difficulties result in insufficient milk intake and suboptimal weight gain [1012]. If the difficulty latching is related to symptomatic ankyloglossia, releasing the tongue has been shown to improve nursing $[13,14]$. Furthermore, depending on the severity of the ankyloglossia, it has been postulated that children may have other complications, as they grow older. These include speech delays (related to articulation difficulty) and dental hygiene problems (owing to failure of the tongue to provide sufficient oral hygiene), though there is limited evidence in this regard [15].

There are several studies showing a strong association between ankyloglossia and breastfeeding difficulties [16-18]. Messner et al. [1] Studied a total of 1041 neonates in the well-baby nursery who were screened for ankyloglossia. Fifty newborns (5\%) were identified with ankyloglossia. Of the 36 mothers of affected infants who were followed up and who intended to breastfeed, 30 (83\%) successfully breastfed their infants for at least 2 months. This study 
found breastfeeding difficulties were experienced by 9 (25\%) of the mothers of infants with ankyloglossia compared with 1 (3\%) of the control mothers $(\mathrm{P}<0.01)$.

Other studies have additionally demonstrated that a lingual frenotomy, frenuloplasty, or frenulectomy (surgical correction of an abnormal lingual frenulum) in infants with ankyloglossia who had breastfeeding problems yield objective improvements in breastfeeding, as well as the reduction in maternal pain, followed by sustained weight gain $[13,19]$. One comprehensive study measured infants' breastfeeding performance using ultrasound imaging of tongue movement before and after frenulectomy [12]. This study divided infants diagnosed with ankyloglossia into two groups based on latching patterns. In one group infants were found to compress the tip of the nipple, while in the other they were observed to compress the base of the nipple. In both cases, the infants struggled to maintain an effective latch and suck, and both groups were associated with maternal nipple pain while feeding. Furthermore, this study revealed that there was a significant increase in milk production after releasing the tongue with a lingual frenulectomy. This was attributed to the enhanced nursing ability of infant's post-frenulectomy.

Although some infants with clinical ankyloglossia will be symptomatic and struggle with nursing, not all infants with ankyloglossia will have breast-feeding difficulties. Also, many infants have difficulty nursing unrelated to underlying biomechanical deficiencies [20]. There is limited objective data assessing the impact of ankyloglossia on breastfeeding or evaluating changes in infant nursing after procedural interventions for ankyloglossia. Therefore, a significant number of infants may undergo unnecessary surgical procedures, which may not resolve the feeding difficulty [21].

Despitetheavailable studies, which suggest thepromiseoflingual frenulectomy at reducing breastfeeding difficulties associated with ankyloglossia, there is a paucity of literature, especially prospective controlled studies, to aid healthcare professionals in predicting the risk of feeding difficulty in an infant with ankyloglossia or to help evaluate the efficacy of frenulectomy. Additionally, there is no consensus on the optimal way to classify ankyloglossia [14]. Several classification systems have been published, but none are consistently used and many are difficult for routine clinical applications. Many healthcare providers use measurements from the tip of the tongue to the frenulum attachment at the floor of the mouth; however, precise measurement of the distance from the origin of the tongue to its insertion site can be very difficult to perform on an infant and is impractical in an office setting. One of the more commonly used classification systems is the Coryllos classification. This is based upon the measurement of the length of the frenulum and denotes 4 classes of ankyloglossia. The Kotlow and revised Kotlow classification also use measurements from the origin to insertion site however they have been shown to have poor interrater reliability [22,23]. Other systems, like the Hazel baker Assessment Tool for Lingual Frenulum Function (HATLFF) and the Bristol Tongue Assessment Tool (BTAT) incorporate tongue function into the classification, but these grading scales are complex and time intensive, making them impractical for normal clinical use.

As the classification, consequence, and treatment outcomes of ankyloglossia cannot be sufficiently explained from the available literature, a novel method for real-time and quantitative measurement of infant latching (specific to ankyloglossia) is required. Furthermore, a certified standard of the severity of ankyloglossia and breastfeeding consequences should be developed and practiced. Lastly, the necessity and efficacy of the frenulectomy procedure should be quantitatively addressed through prospective controlled studies. This will hopefully provide healthcare professionals with appropriate information to further our understanding and management of symptomatic ankyloglossia.

\section{Conflicts of Interest}

There are no conflicts to declare.

\section{Acknowledgements}

We thank the Dalio Institute of Cardiovascular Imaging for their support and funding.

\section{References}

1. Messner AH, Lalakea ML, Aby J, Macmahon J, Bair E (2000) Ankyloglossia: incidence and associated feeding difficulties. Archives of Otolaryngology-Head \& Neck Surgery 126(1): 36-39.

2. Ngerncham S, Laohapensang M, Wongvisutdhi T, Ritjaroen Y, Painpichan $\mathrm{N}$, et al. (2013) Lingual frenulum and effect on breastfeeding in Thai newborn infants. Paediatrics and international child health 33(2): 8690 .

3. Ricke LA, Baker NJ, Madlon-Kay DJ, DeFor TA (2005) Newborn tonguetie: prevalence and effect on breast-feeding. J Am Board Fam Pract 18(1): 1-7.

4. Hogan M, Westcott, C, Griffiths M (2005) Randomized, controlled trial of division of tongue-tie in infants with feeding problems. J Paediatr Child Health 41(5-6): 246-250.

5. Segal LM, Stephenson R, Dawes M, Feldman P (2007) Prevalence, diagnosis, and treatment of ankyloglossia: methodologic review. Can Fam Physician 53(6): 1027-1033.

6. Jones G, Steketee RW, Black RE, Bhutta ZA, Morris SS, Bellagio Child Survival Study Group (2003) How many child deaths can we prevent this year?. The lancet 362(9377): 65-71.

7. Belfield CR, Kelly IR (2012) The benefits of breast feeding across the early years of childhood. Journal of Human Capital 6(3): 251-277.

8. Marincola FC, Dessì A, Corbu S, Reali A, Fanos V (2015) Clinical impact of human breast milk metabolomics. Clinica Chimica Acta 451: 103-106.

9. Nitsch EK, Humphrey LT, Hedges RE (2011) Using stable isotope analysis to examine the effect of economic change on breastfeeding practices in Spitalfields, London, UK. Am J Phys Anthropol 146(4): 619-628.

10. Schlatter SM, Schupp W, Otten J E, Harnisch S, Kunze M, et al. (2019) The 
role of tongue-tie in breastfeeding problems-A prospective observational study. Acta Paediatrica 108(12): 2214-2221.

11. Spencer J, Abrams SA, Drutz JE, Hoppin AG (2015) Common problems of breastfeeding and weaning.

12. Geddes DT, Langton DB, Gollow I, Jacobs LA, Hartmann PE, et al. (2008) Frenulotomy for breastfeeding infants with ankyloglossia: effect on milk removal and sucking mechanism as imaged by ultrasound. Pediatrics 122: E188-E194.

13. Martinelli RLDC, Marchesan IQ, Gusmao RJ, Honorio HM, Berretin-Felix G (2015) The effects of frenotomy on breastfeeding. Journal of Applied Oral Science 23(2): 153-157.

14. Olivi G, Signore A, Olivi M, Genovese MD (2012) Lingual frenectomy: functional evaluation and new therapeutical approach. Eur J Paediatr Dent 13(2): 101-106.

15. Chinnadurai S, Francis DO, Epstein RA, Morad A, Kohanim S, et al. (2015) Treatment of ankyloglossia for reasons other than breastfeeding: a systematic review. Pediatrics 135(6): e1467-e1474.

16. Hong P, Lago D, Seargeant J, Pellman L, Magit AE, et al. (2010) Defining ankyloglossia: a case series of anterior and posterior tongue ties. Int J Pediatr Otorhinolaryngol 74(9): 1003-1006.

17. Pransky SM, Lago D, Hong P (2015) Breastfeeding difficulties and oral cavity anomalies: the influence of posterior ankyloglossia and upper-lip ties. Int J Pediatr Otorhinolaryngol 79(10): 1714-1717.

18. Haham A, Marom R, Mangel L, Botzer E, Dollberg S (2014) Prevalence of breastfeeding difficulties in newborns with a lingual frenulum: a prospective cohort series. Breastfeeding Medicine 9(9): 438-441

19. Chaput KH (2013) The Effect of Breastfeeding Difficulties and Associated Supports on Postpartum Depression: a mixed-methods study.

20. Walsh J, Tunkel D (2017) Diagnosis and treatment of ankyloglossia in newborns and infants: a review. JAMA Otolaryngology-Head \& Neck Surgery 143(10): 1032-1039.

21. Messner AH, Lalakea ML (2000) Ankyloglossia: controversies in management. Int J Pediatr Otorhinolaryngol 54(2-3): 123-131.

22. Coryllos E, Genna CW, Salloum AC (2004) Congenital tongue-tie and its impact on breastfeeding. Breastfeeding: Best for Mother and Baby 1-6. 